\title{
DISCURSOS DE ADOLESCENTES SOBRE A VIDA PROFISSIONAL E FAMILIAR: ENTRE O SONHO E A REALIDADE
}

\author{
LUÍSA SAAVEDRA* \\ Maria do Céu Taveira*
}

\begin{abstract}
RESUMO: Na actualidade, um dos maiores desafios que se colocam às mulheres que seguem ou pretendem seguir uma carreira profissional é a conciliação entre a vida familiar e a profissional. Apesar da pertinência actual deste tema na literatura sobre gestão da carreira, é escassa a investigação sobre esta temática na adolescência. Assim, os objectivos deste estudo são avaliar até que ponto as adolescentes têm consciência daquela realidade, bem como os mecanismos a que as mesmas recorrem para gerir a vida profissional e familiar, quando se perspectivam no futuro. Os dados do estudo foram obtidos através de entrevistas semi-estruturadas, realizadas a dezanove alunas do ensino secundário, a frequentar uma escola urbana, no norte de Portugal. A análise e discussão dos resultados foram levadas a cabo com base na análise de discurso.
\end{abstract}

Palavras-chave: Carreira. Género. Adolescência. Análise de discurso.

\section{AdOLESCENTS' OCCUPATIONAL AND FAMILY LIFE DISCOURSES: BETWEEN DREAM AND REALITY}

ABSTRACT: Nowadays, one of the main challenges women must face when making or trying to make a professional choice for life is the conciliation between family life and professional life. In spite of the relevance of this topic in books about career management, scarcity of research about it during adolescence is still evident. This

\footnotetext{
* Professora Auxiliar do Instituto de Educação e Psicologia da Universidade do Minho, Portugal.E-mail: luisasaavedra@sapo.pt

** Professora Auxiliar do Instituto de Educação e Psicologia da Universidade do Minho, Portugal.E-mail: ceuta@mail.telepac.pt
} 
Discursos de adolescentes sobre a vida profissional e familiar: entre o sonho e a realidade

study aims at assessing the consciousness of this process in adolescent girls, as well as how they cope with that task, when they project themselves into the future. Data were collected from nineteen semi-structured interviews carried out with Portuguese girls attending an urban high school in the north of Portugal. The analysis and discussion of results have been conducted with the support of discourse analysis.

Key words: Career. Gender. Adolescence. Discourse analysis.

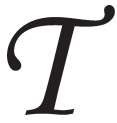

anto a literatura vocacional como a feminista têm considerado a dimensão familiar e profissional como dois dos sistemas centrais da vida adulta (e.g., Fitzgerald \& Harmon, 2001; Super, 1976). A articulação destes dois sistemas ganhou uma nova configuração com o aumento de mulheres prosseguindo uma carreira profissional, assumindo-se esta como o exercício de uma profissão com elevado nível de comprometimento pessoal, com constante actualização de conhecimento e mobilidade social ascendente (Cron, 2001).

O conceito de familia de dupla carreira foi usado pela primeira vez por Rapaport e Rapaport em 1969 (apud Gilbert, 1993) para designar famílias com carreiras inconsistentes com a tradição de género, onde tanto o homem como a mulher simultaneamente prosseguem uma carreira profissional e desenvolvem um estilo familiar em que os filhos e as filhas estão incluídos/as. Neste sentido, as mulheres encarariam a profissão como um objectivo de vida e factor essencial da sua identidade e os homens fugiriam ao padrão tradicional de "chefe de família". Nos inícios dos anos de 1970, as igualdades social, económica e política aparentemente alcançadas nestas famílias levavam a supor que, pelo menos aí, o ideal da igualdade entre homens e mulheres seria concretizado. Contudo, passadas mais de três décadas, apesar de muitos casais terem publicamente assumido relações em que ambos prosseguem uma carreira, o difícil ajustamento entre as responsabilidades da vida familiar - pouco ou nada partilhadas com as figuras masculinas - e profissional tem remetido as mulheres que pretendem seguir ou seguem uma carreira profissional para uma posição de desigualdade a vários níveis (Cinamom \& Rich, 2002, 2002a; Fitzgerald \& Harmon, 2001; Gilbert, 1993; Gilbert, Hallett \& Eldridge, 1994).

A investigação, conduzida na actualidade, aponta para um distinto posicionamento de homens e mulheres face àquelas dimensóes de vida. Num estudo recentemente realizado, Cinamom e Rich (2002) 
detectaram três categorias que caracterizam ambos os sexos face à importância atribuída à família e ao trabalho: o "perfil duplo" inclui pessoas que conferem igual importância aos papéis familiar e profissional; o "perfil trabalho" caracteriza pessoas que valorizam preferencialmente a profissão e o "perfil família" é composto por pessoas que dão maior relevância ao papel familiar.

$\mathrm{Na}$ sequência deste trabalho, Cinamom e Rich (2002a) verificaram que existia um maior número de mulheres que se encaixava no "perfil família” e um maior número de homens que se distribuía pelo "perfil trabalho". Dentro das mulheres havia uma repartição idêntica pelo "perfil família” e pelo "perfil duplo", mas uma representação extremamente reduzida no "perfil trabalho".

$\mathrm{O}$ estado actual das relações de género, neste e noutros contextos, terá um inevitável impacto no modo como as adolescentes concebem e concretizam as respectivas tomadas de decisão de carreira. Efectivamente, a literatura indica que as jovens e mulheres têm tendência para baixar o nível das suas aspirações profissionais devido aos conflitos resultantes da difícil conjugação desta com a vida familiar e doméstica (Leung, Conely \& Schell, 1994). Ainda, segundo Archer (1985), estes conflitos entre trabalho e família estão na base de uma maior dificuldade das jovens em construírem uma identidade vocacional, podendo explicar que se direccionem preferencialmente para cursos considerados tipicamente femininos, onde está patente uma maior flexibilidade de horários e menores exigências e envolvimento com a profissão. Tendo por base estas concepções, o objectivo deste trabalho é analisar as várias concepções das adolescentes sobre a relação entre o domínio profissional e familiar e tentar determinar em que medida estas concepções são influenciadas pelos projectos vocacionais em elaboração ou, pelo contrário, influenciam os mesmos.

\section{Método}

\section{Procedimento}

Os dados foram recolhidos numa escola urbana do norte de Portugal através de entrevistas semi-estruturadas, realizadas a 19 adolescentes do sexo feminino que frequentavam o $11^{\circ}$ ano ${ }^{1}$ de escolaridade e cujas idades variavam entre os 16 e 19 anos de idade, tendo-se controlado a 
Discursos de adolescentes sobre a vida profissional e familiar: entre o sonho e a realidade

origem socioeconómica das alunas (umas de origem elevada e outras de origem baixa) e o seu rendimento académico (alto-rendimento e baixo-rendimento). Assim, foram entrevistadas alunas de origem socioeconómica elevada e com alto-rendimento, alunas de origem social e económica desfavorecida e com alto-rendimento e alunas de origem social e económica desfavorecida e com baixo-rendimento escolar (Saavedra, Taveira \& Rosário, 2004).

\section{As entrevistas}

Para a recolha dos dados foram realizadas entrevistas pessoais semiestruturadas a cada uma das adolescentes, seguindo as indicaçôes da análise de discurso, ou seja, incentivando contextos de diálogo que permitissem às alunas considerar várias possibilidades ou alternativas face aos temas das entrevistas (Wood \& Kroeger, 2000).

Para o trabalho que agora se apresenta, cingimo-nos às questões que directa ou indirectamente resultaram do questionamento sobre o modo como imaginariam as suas vidas no prazo de cinco a sete anos e que nos permitiram inferir sobre as suas concepções acerca do modo de conciliar a futura vida profissional e familiar.

\section{Método de análise}

Os dados foram analisados com recurso à análise de discurso como metodologia de sistematização e interpretação das diferentes formas de abordar a questão de investigação.

Como teoria e metodologia de investigação, a análise de discurso tem uma preocupação central com a linguagem, sendo esta encarada como uma ferramenta de construção da realidade social e psicológica e não como um simples meio de aceder a uma realidade cognitiva existente por detrás das palavras (Parker, 1992, 1997; Potter \& Wetherell, 1987). Neste sentido, construímos uma certa realidade, à medida que falamos com os textos que existem social e culturalmente ao nosso dispor, mas cuja escolha foge, frequentemente, ao nosso controlo (Parker, 1997). Paralelamente, este quadro de referência permite encarar o discurso como uma prática social, significando, assim, que as pessoas utilizam o 
discurso para "fazer coisas" e não unicamente para exprimir ideias. Resumindo, na análise de discurso, o falar e o fazer suportam-se mutuamente na construção de objectos e sujeitos, estabelecendo uma visão da realidade face a outras versões possíveis e competitivas (Willig, 2003).

A análise que seguidamente se apresenta apoiou-se num conjunto de critérios associados a fases tal como foram descritos por Carla Willig (2003).

A primeira fase consistiu em perceber como os objectos discursivos - neste caso, a relação entre vida familiar e profissional - foram construídos. Depois de terem sido identificadas todas as partes do texto onde a interacção vida familiar-profissional era visível, a análise focou-se nas diferentes formas de construir este mesmo objecto, isto é, os discursos.

Seguidamente, foram examinados os contextos em que as várias construções face à conciliação entre vida profissional e familiar surgiram: o que as alunas ganham ou perdem em construir o objecto de um certo modo, num ponto particular do texto, e qual é a sua função.

Num momento seguinte, olhou-se para as posições subjectivas ocupadas pelas diferentes adolescentes, explorando o modo como essas posições abrem ou fecham possibilidades de acção - relacionando, assim, o discurso com a prática - e como condicionam certas formas de "ver o mundo e de estar no mundo, construindo realidades sociais e psicológicas” (Willig, 2003, p. 175).

Depois de um questionamento sobre o que poderia ser dito e feito com diferentes discursos, na fase da subjectividade procurou-se determinar o que poderia ser sentido e pensado através das várias posições subjectivas em que as alunas se colocaram.

$\mathrm{Na}$ secção relativa aos resultados, serão apresentados os vários discursos bem como os contextos sociais, escolares e profissionais que podem influir na sua construção. São ainda considerados alguns sentimentos, ambiguidades e conflitos relativos ao modo como esta realidade é construída. $\mathrm{Na}$ discussão serão analisados os contextos sociais e culturais mais vastos, que podem estar na origem da forma como a realidade é construída pelos vários discursos, bem como as consequências práticas das posições subjectivas manifestadas em termos das relações entre homens e mulheres e da posição da mulher no casal. Finalmente, na conclusão, serão afloradas as possíveis relações dos discursos com os projectos vocacionais delineados e o meio social e cultural de onde são originárias. 
Discursos de adolescentes sobre a vida profissional e familiar: entre o sonho e a realidade

\section{Resultados}

A análise das entrevistas permitiu identificar cinco formas distintas de construir a interacção familiar-profissional: (i) relação profissional-familiar ausente; (ii) relação profissional-familiar sem solução; (iii) adiamento da vida familiar; (iv) equilíbrio profissional-familiar; (v) relação profissional-familiar idealizada.

Alguns discursos aludem unicamente à vida privada (amigos, família, casamento ou ausência dele, ter ou não ter filhos, por exemplo), sem qualquer referência explícita ao domínio profissional. Outros discursos fazem uma referência espontânea e directa à conciliação entre a sua vida afectiva, familiar e profissional, embora se salientem diferentes posicionamentos quanto ao grau de reflexão, bem como às soluções encontradas para enfrentar esta relação.

\section{Relação profissional-familiar ausente}

Nos excertos que integram este grupo de adolescentes, apenas num caso se faz uma breve alusão à vida profissional (Manuela ${ }^{2}$ - "em termos profissionais imagino-me bem"), mas em nenhum dos excertos a vida profissional é perspectivada relativamente a outras dimensōes da carreira.

MANUELA (Línguas) - Em termos profissionais imagino-me bem, sempre... depois em termos pessoais também, não sei... Se calhar casada, se calhar não... eu gostava de me casar, não é... mas são coisas que não se escolhem... surgem... mas imagino-me com uma vida estável (...).

GABRIELA (Medicina) - Ah! E ter a minha casa, não sei... eu acho que, não é que eu não goste muito dos meus pais, mas queria ter casa assim logo 20 e tal anos 24 , ter a minha casa, ter as minhas coisas, claro que a minha mãe vai estar sempre ao lado para me ajudar... mas não sei, queria ter uma independência total, se calhar depois não é lá muito boa ideia, mas gostava de ter a minha casa...

RUTE (Línguas) - Não. Quero, quero ter filhos de certeza, quero casar, não quero ficar em casa dos meus pais... quero ser independente... querer sair de casa dos meus pais isso não implica que queira ser uma pessoa solitária ou sozinha, ou não queira ter filhos, porque eu quero, nada disso...

A primeira preocupação manifesta-se relativamente à independência perante os pais, que pode ser concretizada através do casamento (Manuela e Rute) ou de uma forma mais vaga, como é o caso da Gabriela. 
Este último caso reflecte, aliás, alguma ambiguidade face à sua independência, oscilando entre definir-se pela ajuda materna ou uma independência total sobre cujas vantagens se revela duvidosa.

Estas três adolescentes apresentavam, até ao momento das entrevistas, um alto-rendimento académico, que tinha sido uma constante dos seus percursos escolares. Simultaneamente, eram provenientes de um meio familiar beneficiado do ponto de vista económico, social e cultural. Saliente-se, contudo, que os seus projectos escolares e profissionais não se afastam muito do que poderiam ser habitualmente consideradas profissões tipicamente femininas.

\section{Relação profissional-familiar sem solução}

A aluna cujo excerto seguidamente se transcreve, e que apresenta um elevado rendimento académico, bem como um igual estatuto socioeconómico, reconhece que na profissão que projecta seguir poderão existir algumas dificuldades em "ter uma vida pessoal".

DORA (Medicina) - Já, também já pensei nisso... já sei que vai ser um bocado difícil, não é? Porque é aquela coisa dos médicos não terem tempo para ter uma vida pessoal, não é, serem chamados assim no meio... não sei (...). Pois, não é não ter, que eles têm e eu também vou ter e quero ter, só que eles encaram um bocado a falta de tempo... se for médico de urgência como eu quero ser não é, estar sujeita a ser chamada assim a meio da noite e não sei quê... mas lá está... era o que eu gostava de ser, eu não tenho culpa, não sei...

A expressão "eu não tenho culpa" pode significar que esta opção profissional the causa alguma culpabilidade por considerar que irá restringir o tempo a conceder ao domínio familiar. O problema é, contudo, apenas aflorado, não sendo formulada qualquer estratégia de resolução.

\section{Adiamento da vida familiar}

Em todos os três excertos que a seguir se apontam está patente um reconhecimento da dificuldade em gerir a vida profissional e familiar e de que esta última pode interferir de forma dinâmica com a primeira. A esta consciência não parece alheio o facto dos projectos 
Discursos de adolescentes sobre a vida profissional e familiar: entre o sonho e a realidade

profissionais delineados se inserirem num contexto menos tipicamente feminino (engenharia civil, engenharia electrotécnica e arquitectura) e onde o domínio masculino, quer em termos numérico, quer de imagem de prestígio, é ainda predominante.

ISABEL (Engenharia Civil) - Tentar ir viver sozinha.... é uma coisa que eu quero (...). O futuro... o casamento e isso tudo, não vejo tão cedo essas coisas, tenho o futuro profissional primeiro (...). Eu acho que há tempo para tudo e é primeiro a vida profissional, acho que está primeiro que tudo... não, não quer dizer que deixe a minha vida pessoal para trás, mas pode acompanhar, o casamento não é uma coisa prioritária na vida de uma pessoa... (...) agora um casamento tem que ter uma situação financeira sólida, e para quem está a estudar, profissionalmente... quer engrandecer profissionalmente...

MÓNICA (Engenharia Electrotécnica) - Casar, não tão cedo, tenho muito tempo para isso ainda, primeiro quero começar a carreira e tudo e depois penso em casar... [sobre os filhos] Gostava de ter, não muitos... não, mas também é uma coisa para mais tarde, bastante mais tarde... (...). Fim dos 20,30 por aí... (...) acho que também não vou ter maturidade suficiente para cuidar de mim, cuidar do meu marido e ainda cuidar de filhos, não, nem pensar...

SOFIA (Arquitectura) - Fazer coisas na área da decoração interior, estilismo, as possibilidades que me vierem de fazer pequenos cursos, nem que seja de (...), assim no estilo, eu gostava... ou criar, também é uma ideia, criar um atelier para crianças, pintura e assim... andar à volta de tudo o que seja arte... depois a vida sentimental... não acredito que esteja casada nem nada parecido, nessa altura se estiver a viver sozinha, tanto melhor... (...) mas depois com a experiência da vida vejo que as arquitectas têm muito pouco tempo, são pessoas que... têm que estar em obras, dão pouca atenção aos filhos...

Todos estes discursos revelam uma necessidade de independência quanto à família de origem e, paralelamente, o adiar do casamento e do nascimento dos filhos como forma preferencial de abordar e "resolver" esta problemática. De uma maneira bastante clara, o domínio profissional ganha supremacia sobre os restantes: "e para quem está a estudar, profissionalmente... quer engrandecer profissionalmente..." (Isabel); "Gostava de ter, não muitos... não, mas também é uma coisa para mais tarde, bastante mais tarde..." (Mónica); "não acredito que esteja casada nem nada parecido, nessa altura se estiver a viver sozinha, tanto melhor" (Sofia). Esta questão do adiamento do nascimento dos 
filhos pode até levantar conflitos, como está patente no discurso da Sofia quando refere: "(...) têm muitas coisas que eu pensei que se calhar não queria ser arquitecta porque se tiver um filho, um só, vou querer dar-lhe toda a atenção, não é?".

\section{Equilíbrio profissional-familiar}

Uma das adolescentes entrevistadas revela alguma consciência de como a dimensão profissional pode interferir em certas vertentes da vida familiar, mas, ao contrário das colegas referidas na secção anterior, não pretende prescindir de nenhuma dessas dimensões, tentando encontrar um equilíbrio entre ambas e fazendo algumas concessōes em termos profissionais. Este modo de equacionar a questão poderá estar relacionado com um conhecimento bem fundamentado desta área de trabalho, patente na entrevista.

MARIA (Medicina) - Sim, também quero ter, aliás medicina que é um curso que exige muito, eu própria acho que vou estipular regras (...) e uma das regras que eu acho que vou fazer comigo própria é prefiro ganhar menos mas ter uma vida afectiva... porque acho que isso é muito importante, muito para uma pessoa ser bem sucedida porque acho que a felicidade ajuda muito, muito... (...) Sim, sim... de ter o meu tempo para os meus filhos... ter uma hora para chegar a casa, não chegar às não sei quantas da noite, só um dia por semana, claro, ter que fazer uma urgência... mas de resto chegar a... porque eu conheço médicos que fazem isso, chegam a casa a horas, mais ou menos por volta das 6 , têm tempo para estar com os filhos, ter o fim de semana ou então um dia por semana para poder estar...

\section{Relação profissional-familiar idealizada}

A marca fundamental deste discurso parece revelar-se numa forma idealizada de encarar as várias dimensões da vida de adulta, embora se encontre mais presente na Joana. A segunda aluna manifesta alguma consciência de que a maior ou menor dificuldade estará dependente do projecto vocacional a implementar.

JOANA (Fisioterapia) - Penso em casar mas quando chegar a altura, quando tiver a minha vida estável, quando já souber aquilo que quero mesmo 
Discursos de adolescentes sobre a vida profissional e familiar: entre o sonho e a realidade

da vida, quando tiver o meu dinheiro ou assim, (...) mas assim quando já tivesse um emprego, a minha casa, gostava de casar (...). Tem que haver tempo para tudo, tem que haver tempo para o trabalho, sem trabalho não há dinheiro, não há dinheiro não há vida, tem que se jogar tudo, tem que haver um bocadinho de tempo para o trabalho, tem que haver um bocadinho de tempo para os filhos, e um bocadinho de tempo para o marido... e para os amigos também., também fazem parte da vida..

LIA (Enfermagem ou Serviço Social) - Eu acho que não [não acha que vai ser difícil conciliar a vida profissional com a carreira] mas também é conforme o emprego que tiver não é? Mas eu acho que não... Se tiver capacidades para isso, há infantários ou isso e de manhã à noite posso os pôr lá ou isso, e se não tiver ninguém, por exemplo a minha mãe pode tratar dos meus filhos ou isso... mas se não puder tenho o infantário, mas tenho que equilibrar tudo, emprego, filhos e vida de casa e isso, tenho que equilibrar tudo... [relativamente a enfermagem]. Era, muito mais... pelo que me dizem é muito mais complicado e eu conheço uma senhora que ela... é complicado... passa noites assim em branco e depois está pouco tempo com as filhas e isso... é mais o marido que faz a vida dela...

Em qualquer um dos casos, a profissão, o casamento, a vida familiar em geral, bem como os filhos são aspectos ponderados e claramente incluídos nos seus projectos de vida. No entanto, a Joana parece encarar de forma bastante optimista esta conciliação, confundindo o "deve" com o "ser", enquanto a Lia se apresenta mais consciente das maiores dificuldades de umas opções face a outras. A esta forma de lidar com a situação não parece alheio o facto destas alunas serem provenientes de meios sócioculturais mais desfavorecidos e se relacionarem, provavelmente, com figuras maternas com posturas mais convencionais face à partilha das tarefas domésticas com o outro elemento do casal.

\section{Discussão}

$\mathrm{Na}$ discussão dos resultados, que seguidamente se apresenta, está subjacente a ideia de que a construção dos discursos anteriormente apresentados interfere com a forma como estas alunas vêem o mundo e actuam face a ele, nomeadamente no que diz respeito às relações de género no domínio profissional e familiar. Sendo assim, torna-se necessário inserir a análise efectuada dentro de um determinado contexto social e cultural, que o trabalho científico tem revelado. 
A investigação levada a cabo neste domínio tem indicado que as pessoas valorizam diferentemente a dimensão pessoal e profissional. Em 1974, Richardson distinguiu entre o conceito de "motivação para o trabalho" e de "orientação para a carreira", tendo definido o primeiro como o simples desejo de trabalhar fora de casa, embora não dando prioridade a esse papel, e a "orientação para a carreira" como a tendência para fazer do trabalho o centro de interesse dominante da vida e para encarar as tarefas domésticas como secundárias. A investigação conduzida por Cinamom e Rich (2002a) revela que o domínio doméstico ainda continua a ser a principal fonte de orientação das mulheres, ainda que algumas o consigam conciliar de forma equilibrada com o domínio profissional.

Este estudo permite encontrar algumas semelhanças com o trabalho desenvolvido pelas autoras acima referidas. Dois dos discursos identificados ao longo deste trabalho coincidem visivelmente com a tipologia encontrada por Cinamom e Rich (2002a): o discurso que designamos por "adiamento da vida familiar" aproxima-se do "perfil trabalho", enquanto o discurso "equilíbrio profissional-familiar" se assemelha ao "perfil duplo". Por outro lado, o discurso "relação profissional-familiar idealizada" apresenta alguma afinidade com o "perfil família”, apesar de não ser decalcável de forma tão directa como os dois anteriores. Esta forma de construir a realidade profissão-família encontra-se próxima do conceito de motivação para o trabalho (Richardson, 1974), pois a profissão não se assume como uma dimensão estruturante da identidade.

Os restantes dois discursos - "relação profissional-familiar ausente" e "relação profissional-familiar sem solução" - parecem enquadrar-se, essencialmente, num perfil de jovens adolescentes que, afastadas do quotidiano feminino adulto (ou em contacto com um ambiente familiar onde as empregadas domésticas asseguram estas tarefas), ainda não amadureceram devidamente esta problemática. Tendo em conta que o trabalho de Cinamom e Rich (op. cit.) foi levado a cabo com mulheres e homens adultos, é compreensível que estes perfis estejam ausentes no trabalho das autoras e se tornem salientes neste estudo.

Esta interpretação é, aliás, corroborada - principalmente no discurso "relação profissional-familiar ausente" - por uma investigação realizada por Gilbert et al. (1991), na qual as autoras verificaram que poucas estudantes tinham consciência do significado de prosseguir uma carreira desempenhando simultaneamente funções parentais e maternais, embora conferissem elevado significado a estas duas dimensões de vida. 
Discursos de adolescentes sobre a vida profissional e familiar: entre o sonho e a realidade

Por outro lado, a acentuada preocupação com a aquisição da independência face à figura materna e paterna parece ocupar toda a preocupação das jovens deste estudo, impedindo-as de ponderar devidamente outras dimensões da vida adulta.

No discurso "relação profissional-familiar sem solução", a falta de estratégias para lidar com a situação parece ter subjacente a ideia de que só os homens podem fazer essas opções, pois estas condicionam em grande medida a disponibilidade para a vida familiar. Da afirmação de que "era o que eu gostava de ser... eu não tenho culpa" subentende-se alguma culpabilidade perante o seu projecto de carreira que, ao mesmo tempo, pode justificar invocando o discurso corrente e da psicologia vocacional: devemos escolher as actividades pelas quais nos sentimos mais motivadas e para as quais os nossos interesses são mais elevados.

No discurso dominado pela ideia do adiamento da vida familiar fica visível a concepção de que vida familiar e profissional são incompatíveis, pelo menos no início da carreira. No caso da Isabel, gera-se alguma confusão, pois se, por um lado, defende que o casamento pode esperar para mais tarde, não tendo que ser uma prioridade na vida das pessoas, por outro parece encarar o casamento como algo que tem que ocorrer durante a vida universitária: "agora um casamento tem que ter uma situação financeira sólida, e para quem está a estudar.., profissionalmente... quer engrandecer profissionalmente...”.

Ainda no âmbito do discurso "adiamento da vida familiar", outra jovem (Mónica) afirma a dado momento: “(...) acho que também não vou ter maturidade suficiente para cuidar de mim, cuidar do meu marido e ainda cuidar de filhos, não, nem pensar...”. Esta formulação denota uma imagem profundamente convencional dos papéis familiares, considerando não só que a mulher tem de cuidar dos filhos, sem qualquer suporte do conjugue, bem como ainda cuidar do marido. Nesse sentido, a construção discursiva da Sofia parece completar a ideia da colega anterior, quando afirma "se estiver a viver sozinha tanto melhor" como se essa tarefa de cuidar de si, dos filhos e do marido fosse demasiado ambiciosa para uma única pessoa, só exequível por uma "super-mulher". Aliás, esta tarefa de conciliação afigura-se-lhe de tal modo complexa que chega mesmo a considerar a possibilidade de abandonar o seu projecto face à carreira para poder dedicar-se integralmente a um filho que venha a nascer.

Um dos objectivos da análise de discurso é não só interpretar o que está patente na forma como as pessoas falam do objecto do discurso, mas 
também o que está ausente nessa forma de falar (Parker, 1997). Uma das principais ausências discursivas ao longo de todas as entrevistas é a participação da figura masculina na vida familiar, quer sobre a forma de ajuda ou de partilha das tarefas domésticas, quer do cuidado com os filhos e/ou filhas. Este discurso pertence não só ao domínio da teoria feminista, como circula em vários espaços informais em que este tema se torna alvo de debate. Contudo, em nenhum momento das entrevistas esta presença é realçada ou sequer aflorada. Fala-se na ajuda das mães (Gabriela: "claro que a minha mãe vai estar sempre ao lado para me ajudar"), no recurso à mãe ou ao infantário para tomar conta dos filhos (Lia: "por exemplo a minha mãe pode tratar dos meus filhos ou isso... mas se não puder tenho o infantário"), mas nunca a uma figura masculina de marido ou companheiro. E, no entanto, a figura do marido está presente nos discursos, mas com outra função: "cuidar do meu marido", "e um bocadinho de tempo para o marido", "... é mais o marido que faz a vida dela..." (Lia falando de uma enfermeira). Mesmo quando a Maria (aluna que procura um equilíbrio entre a vida familiar e profissional) fala em ganhar menos dinheiro para poder dedicar mais tempo à família, não é colocada a hipótese de que o marido faça o mesmo ou que haja uma partilha de tarefas entre ambos.

Em termos de prática do discurso (Willig, 2003), todas as construções discursivas parecem conduzir a um aprisionamento destas alunas ou em projectos vocacionais menos ambiciosos ou num adiar de vida pessoal, mesmo nos casos em que estas duas possibilidades não se apresentam de forma tão explícita. A possibilidade de conceber a partilha de tarefas familiares com uma presença masculina (ainda que na vida real tal não se viesse a confirmar) permitir-lhes-ia um abrir de horizontes mais flexível em termos profissionais e carregado de menos angústias e culpabilidade pessoal. Esta ausência demonstra que, possivelmente, são incapazes de conceber relações paritárias entre homens e mulheres, sobretudo no domínio mais íntimo, possivelmente porque esta é também uma forma de luta pela igualdade menos visível em lugares públicos, onde os principais combates se centram, no momento actual português, na questão das cotas para a vida política e na legalização do aborto.

\section{Conclusões}

Ao longo deste trabalho podem-se verificar diferentes formas de abordar e construir uma determinada realidade acerca da conjugação 
entre vida profissional e familiar. Independentemente da forma assumida pelos discursos, torna-se notório que o modo de perspectivar a relação entre o domínio familiar e profissional se afigura uma dimensão importante no processo vocacional para muitas adolescentes. Mesmo naquelas que não fazem referência directa a esta problemática podemos levantar a hipótese de que ela lhes esteja subjacente e possa ter influenciado a opções por trajectos socialmente considerados mais tipicamente femininas.

O nível de rendimento escolar destas jovens e a sua origem social, cultural e económica foram controlados a fim de se analisar em que medida estes contextos poderiam interpor-se com a construção dos discursos. Embora se tenha verificado que estas variáveis não têm uma interferência directa na produção discursiva utilizada pelas alunas, indirectamente parecem contribuir para os seus trajectos vocacionais. Assim, as alunas com um alto-rendimento escolar (independentemente da sua classe social de origem) têm acesso a projectos profissionais de maior prestígio social, ficando as alunas com baixo-rendimento remetidas para caminhos menos ambiciosos deste ponto de vista. Consequentemente, algumas perspectivam uma carreira, enquanto outras se limitam a escolher um emprego.

Paralelamente, parece ser possível inferir que os discursos produzidos face a esta temática se afiguram, para além de questões de desenvolvimento pessoal em geral e vocacional em particular, estar em íntima ligação com os projectos vocacionais que as adolescentes estão a equacionar para o futuro. Assim, estes projectos associados a domínios eminentemente masculinos, como é o caso da engenharia e arquitectura, parecem desenhar uma prevalência da vida profissional, enquanto os trajectos orientados para sectores onde as mulheres são predominantes (ensino, letras) ou em número equivalente (como medicina) permitem uma maior variedade de formas de encarar a problemática, dando azo a que a individualidade de cada aluna se torne mais determinante.

Em resumo, parece ser plausível afirmar que o rendimento académico nas adolescentes entrevistadas se afigura como o principal construtor de uma determinada realidade sobre o domínio familiar e profissional, conduzindo ao prosseguimento de uma carreira (ou não) e possibilitando uma relação conjugal futura de dupla carreira. Seguidamente, o domínio profissional escolhido (mais ou menos feminino, mais ou menos exigente) parece ter o lugar seguinte na construção de uma determinada concepção sobre a vida familiar futura. Fica, contudo, por 
determinar - porque tal não era objectivo deste estudo - o peso a atribuir à percepção de facilidade ou dificuldade em conjugar o domínio familiar e profissional no processo de tomada de decisão e até que ponto certas opções terão sido deixadas de lado para prosseguir caminhos considerados de mais fácil conciliação.

É de considerar a importância de resultados deste tipo serem alargados a populações mais extensas, utilizando eventualmente metodologias quantitativas que permitam abarcar um maior número de alunas, como já aconteceu com estudos realizados noutros países (e.g., Gilbert et al., 1991; Gilbert, 1993).

Para finalizar, e em termos de intervenção, saliente-se o importante papel a desempenhar pelos conselheiros e conselheiras de orientação, no sentido de avaliar até que ponto certos trajectos vocacionais estão a ser deixados de lado por determinadas concepçôes de vida familiar. Simultaneamente, compete a estes profissionais sensibilizar as adolescentes para uma forma mais flexível de encarar esta problemática, promovendo a sua reflexão sobre formas alternativas de conceber a interacção profissão-família, nomeadamente sobre o papel da figura masculina na família e a eventual importância de discutirem esta questão no âmbito de uma relação amorosa, como salienta Gilbert (1993). Intervençôes do âmbito da orientação vocacional mais sensíveis a esta temática poderiam contribuir para a promoção de uma maior igualdade de género no contexto vocacional.

Recebido em março de 2006 e aprovado em dezembro de 2006.

\section{Notas}

1. O ensino não-superior em Portugal está organizado no ensino básico obrigatório, de 9 anos de escolaridade, e no ensino secundário, composto por mais três anos. As alunas entrevistadas encontravam-se no ano intermédio do ensino secundário $\left(11^{\circ}\right.$ ano de escolaridade).

2. Os nomes utilizados ao longo deste texto são meramente ficcionais.

\section{Referências bibliográficas}

ARCHER, S.L. Career and/or family: the identity process for adolescent girls. Youth and Society, Victoria, n. 16, p. 289-314, 1985. 
Discursos de adolescentes sobre a vida profissional e familiar: entre o sonho e a realidade

CINAMON, R.; RICH, Y. Profiles of attribution of importance to life roles and their implications for the work-family conflict. Journal of Counseling Psychology, Washington, DC, n. 49, p. 212-220, 2002.

CINAMON, R.; RICH, Y. Gender differences in the importance of work and family roles: implications for work-family conflict. Sex Roles, New York, v. 47, n. 11/12, p. 531-541, 2002a.

CRON, E.A. Job satisfaction in dual-career women at three family life cycle stages. Journal of Career Development, London, v. 28, n. 1, p. 1728, 2001.

FITZGERALD, L.F.; HARMON, L.H. Women's career development: a postmodern update. In: LEONG, F.T.L.; BARAK, A. (Org.). Contemporary models in vocational psychology. Mahwah, NJ: Lawrence Erlbaum, 2001. p. 207-230.

GILBERT, L.A. Two careers, one family. Newbury Park: Sage, 1993.

GILBERT, L.A. et al. Assessing perceptions of occupational family integration. Sex Roles, New York, v. 24, p. 107-114, 1991.

GILBERT, L.A.; HALLETT, M.; ELDRIDGE, N.S. Gender and dual career families: implications for the career counselling of women. In: Walsh, W.P.; Osipow, S.H. (Org.). Career counselling for women. Hillsdale, NJ: Erlbaum, 1994. p. 135-164.

LEUNG, S.A.; CONELY, C.W.; SCHELL, M.J. The careers and educational aspirations of gifted high school students: a retrospective study. Journal of Counseling and Development, Alexandria, n. 72, p. 298303, 1994.

PARKER, I. Discourse dynamics: critical analysis for social and individual psychology. London: Routledge, 1992.

PARKER, I. Discursive psychology. In: Fox, D.; Prilleltensky, I. (Org.). Critical psychology: an introduction. London: Sage, 1997. p. 284-298.

POTTER , J.; WHETERELL, M. Discourse and social psychology. London: Sage, 1987.

RICHARDSON, M.S. The dimensions of career and work orientation in college women. Journal of Vocational Behavior, New York, n. 5, p. 161$172,1974$. 
SAAVEDRA, L.; TAVEIRA, M.C.; ROSÁRIO, P. Classe social no feminino: percursos e (co)incidências. Braga: Centro de Investigação em Educação, Universidade do Minho, 2004.

SUPER, D.E. Career education and the meaning of work. Washington, DC: Office of Education, 1976.

WILLIG, C. Discourse analysis. In: Smith, J.A. (Org.), Qualitative psychology: a practical guide to research methods. London: Sage, 2003. p. 159-183.

WOOD, L.A.; KROEGER, R.O. Doing discourse analysis: methods for studying action in talk and text. London: Sage, 2000. 